\title{
浅谈在民法婚姻家庭编中规范夫妻债务关系
}

\author{
Discussion on Regulating the Debt Relation Between Husband and \\ Wife in the Marriage and Family Code of Civil Law \\ 刘娟 \\ Juan Liu
}

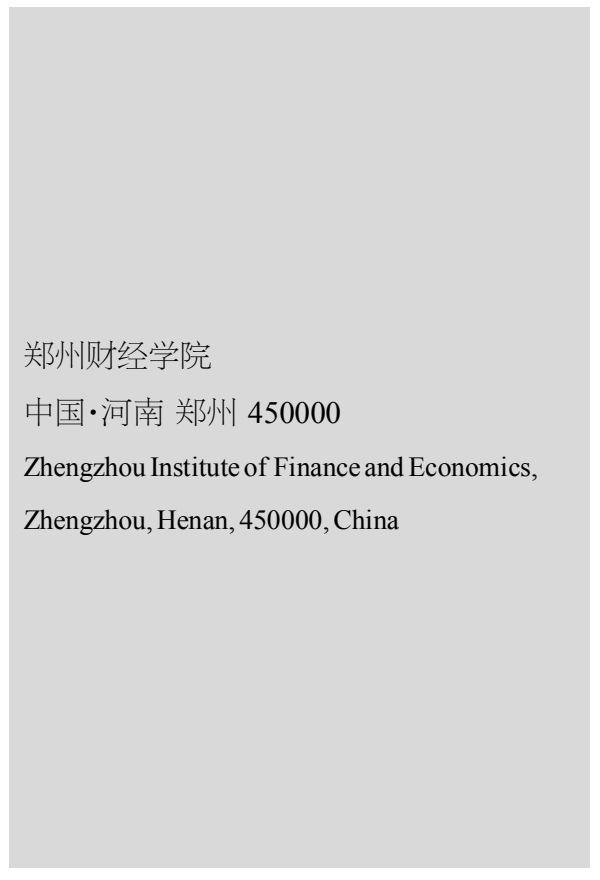

【摘 要】《中华人民共和国民法典》中明确规定, 在中国每位合法公民都有享受自身独立 财产的权利, 尤其在现阶段社会主义市场经济不断发展的产业时代背景下, 如何规范夫妻 的债务关系也成为现阶段中国基层机构和相关主管部门的核心发展方向。鉴于此,论文主 要阐述了现阶段中国《婚姻法》存在的弊端, 并对其完善建议进行了全面探析, 以期为国民 婚姻债务关系提供可靠保障。

【Abstract】The Civil Code of the People's Republic of China clearly stipulates that every lawful citizen in China has the right to enjoy his own independent property. Especially in the background of the industrial era of the continuous development of socialist market economy at this stage, how to regulate the debt relationship between husband and wife has also become the grass-roots state institutions and institutions in China at this stage. The core development direction of relevant competent departments. In view of this, the paper mainly elaborates the drawbacks of China's Marriage Law at this stage, and makes a comprehensive analysis of its improvement proposals, in order to provide a reliable guarantee for the national marriage debt relationship.

【关键词】法律; 存在问题; 完善意义; 完善策略

【Keywords 】law; existing problems; improving significance; improving strategies 【DOI】10.36012/emr.v1i2.596

\section{1 现阶段中国《婚姻法》中存在的弊端}

传统《婚姻法》的确立, 是建立在“男方赚钱养家,女方洗 衣带娃”的旧社会思想下,而随着社会主义市场经济的不断 发展与进步, 人们的思想也发生了显著变化, 现代社会女性 在推动社会发展中也发挥了十分重要的作用。因此,在新时 代背景下, 《婚姻法》中某些规章条例也存在严重的不足, 各 种法则漏洞也亟待完善, 其中, 夫妻债务问题作为一直以来 《婚姻法》中探讨的重点和难点, 其完善策略的制定更加受到 了社会各界及人们的广泛关注和高度重视。
根据相关数据调查可知, 现阶段中国现行的《婚姻法》还 是 2001 年修订的, 且其中大部分内容仍延续 1980 年《婚姻 法》的条例与法则, 导致其与当前社会发展之间的矛盾愈发显 著。尤其是目前每位公民享有独立支配自己财产的权利, 夫妻 双方财产也大多各自存储, 与传统社会相比, 其共同生活内容 变得较为复杂, 而共同债务也不再容易把控。但就目前而言, 对于夫妻共同债务的认定仍只有在离婚一章中第四十一条有 所规定, 即离婚时, 原为夫妻共同生活所负的债务, 应当由夫 妻双方共同偿还。通过上述分析可知, 夫妻双方结婚后, 两人 
都不愿与对方债务捆绑到一起, 但不可否认的是, 现行的《婚 姻法》未对其相关内容作出明确规定, 使得对方在离婚时, 债 务纠纷案例屡见不鲜, 对社会的稳定和谐发展造成极为不利 的影响。除此之外, 1980 年《婚姻法》制定时, 其社会背景相对 简单, 人权主义的影响力也相对较小, 且当时人们的生活水平 相对较低, 城镇居民支配收人不到 500 元, 对于共同债务的把 控力较强。但近年来随着社会主义市场经济的不断发展和城 市化、工业化建设进程的不断加快, 家庭财富的迅速增长导致 相关部门对债务的把控能力越来越低, 在这种发展趋势下, 倘 若夫妻关系存续期间, 一方在对方不知情情况下存在严重的 债务, 按照现行的《婚姻法》, 不仅严重损害了不知情一方的合 法权益, 对于社会的整体发展而言也是极为不利的 ${ }^{[1]}$ 。

\section{2 夫妻债务关系相关法则完善的积极意义}

通过上述分析可知, 在《婚姻法》中对于夫妻财产之间的 关系是极为重要的, 为此, 相关部门也对夫妻财产制度及个人 财产制度做了较详细的法律条文, 以避免后续各种问题的发 生。但不可否认的是, 《婚姻法》的更新速度较慢, 与国家社会 的整体发展存在差距, 导致现行的相关法律条例与法则可能 并不适用于当今的中国, 甚至近年来网上还出现了“防火防盗 防配偶”的言论。因此, 对中国现行《婚姻法》中关于夫妻共同 债务之间的关系进行修改和完善是极为必要的。为从根本上 有效地解决司法实践过程中争议较大的夫妻双方共同债务认 定问题, 最高人民法院发布的《关于审理涉及夫妻债务纠纷案 件适用法律有关问题的解释》中明确规定一一夫妻双方共同 签字、夫妻一方事后追认及夫妻一方所负债务用于夫妻共同 生活时的债务属于夫妻共同债务, 在离婚后仍需夫妻双方共 同负担; 而倘若是一方在对方不知情情况下所负债务且无法 证明债务用于夫妻共同生活时, 所背负的债务属于个人债务, 离婚后由个人自行承担。总而言之, 这种法律的完善与改进, 不仅有利于引导民事商事主体主动规范交易行为, 还保障了 不知情一方的合法权益, 是真正解决夫妻债务纠纷的重要途 径 ${ }^{22]}$ 。从目前来看, 在新时代背景下, 随着各种新时代思想的 渗透与娱乐休闲方式的增加, 人们对于伴侣的重视度也在不 断降低, “丁克家族”、“灵魂伴侣”、“不婚族”等婚姻观念的存 在也极大地降低了年轻人对于婚姻的信任度, 在婚后依旧我 行我素, 未能正确地对待夫妻双方的婚姻关系, 由此也增加了 债务的总金额, 对于社会的稳定性发展也造成了极为不利的 影响。而经大量的调研数据分析可知, 改善修订夫妻债务关系 对于改善年轻人对婚姻态度及维持社会稳定发展而言, 都有 很大的现实意义。

\section{3 完善《婚姻法》中夫妻共同债务关系的 优化建议}

\section{1 在立法过程中融入社会主义核心价值观}

中国共产党第十九次全国代表大会明确指出, 在当前社 会主义建设过程中, 各项决策的制定与实施都必须融入社会 主义核心价值观, 各项法律规章制度的确立亦是如此。尤其是 在当前, 各种经济社会群体的出现给人们的思想带来了巨大 影响, 而近年来随着离婚率的不断增加, 如何有效地避免各种 债务纠纷也成为相关主管部门的核心发展方向。目前来看, 夫 妻债务作为婚姻家庭关系的重要内容, 在对其进行规范时, 不 仅需将“自由、平等、公正、法治”的社会主义核心价值观融入 其中, 与此同时, 为确保社会形成一种平等公正的氛围, 在进 行债务的规范时, 各部分还需遵循“平等参与、共同决策、权责 对等”的原则, 以期为社会的稳定和谐发展奠定良好基础。

\section{2 确保法律法规落实到实处, 债务规范还需兼 顾婚姻安全}

在进行夫妻债务规范过程中, 为从根本上避免纸上谈兵 问题的产生, 在确保相关法律法规时, 相关主管部门需以解决 问题为导向, 积极回应现阶段《婚姻法》中存在的问题, 从而最 大程度地避免各种问题的产生, 并确保每位中国合法公民都 享有合法的权利。除此之外, 在处理夫妻债务的过程中, 为最 大程度地降低因生产经营而给家庭带来的社会风险, 在对夫 妻双方债务进行规范时, 立法机关还需综合考虑婚姻安全及 交易安全, 从而避免商事领域中的相关内容直接应用于家庭 领域中, 以期在切实保障各种问题处理效果最佳的基础上, 实 现利益兼顾的立法目的。

\section{4 结语}

通过上述分析可知, 新时代的来临在一定程度上虽然从 根本上有效改善了当前中国的发展现状, 提高了人们的物质 生活质量, 但各种思想的渗透也极大地降低了青少年对于婚 姻的信任度, 离婚率不减反增。而在离婚案件中, 债务纠纷一 直以来是影响社会和谐稳定发展的重要因素, 为从根本避免 上述问题的产生, 对夫妻债务进行明确规范是推进社会和谐 发展的重要基础和根本前提。

\section{参考文献}

[1]孔凡锦,王文瀚,刘迪.如何区分正当的债权行使与犯罪的界限 [N].广西壮族自治区南宁市公安局兴宁分局法制大队人民公安报, 2017,12 (15):222-224.

[2]刘艳云, 张海洋, 徐晓曦. 婚姻家庭调解的效果评估与完善建 议——以北京市西城区为例[J].新视野,2017,15(22):106-109. 